\title{
An overview of the first 50 years of transglutaminase research
}

\author{
Simone Beninati - Carlo M. Bergamini · \\ Mauro Piacentini
}

Published online: 28 November 2008

(C) Springer-Verlag 2008

The IX Conference on Transglutaminase and Protein Crosslinking was brilliantly organized by Said El Alaoui in Marrakesh, in the early days of September 2007. As in our tradition, Martin Griffin resumed hot points emerging at the conference in his final remarks. He reminded us that 2007 was the year of the 50th anniversary of the discovery of transglutaminases by Heinrich Waelsch in USA (Sarkar et al. 1957). We reasoned that probably most young researchers in the field did never hear the names of the early chief scientists in the field and that they were not aware of the sequence of discoveries that paved the development of transglutaminase research from the original steps to the present stage. In our opinion, this anniversary represents the right occasion to circulate this information, and more importantly to collect interested people around a virtual table to image the future of the field. Through the interest of Simone Beninati, it was possible to focus a special issue of the journal Amino Acids to transglutaminase, with main attention to transglutaminase 2, the "bête noire in transglutaminase research" as Laszlo Lorand defined this protein in a review a few years ago (Lorand and Graham 2003).

\section{Early years}

Heinrich Waelsch, a Czech immigrant, reached United States in late 1930s and found a job at the College of

S. Beninati $(\bowtie) \cdot$ M. Piacentini

Department of Biology, University of Rome "Tor Vergata",

Via della Ricerca Scientifica, 00133 Rome, Italy

e-mail: beninati@bio.uniroma2.it

C. M. Bergamini

Department of Biochemistry and Molecular Biology,

University of Ferrara, Ferrara, Italy
Physicians and Surgeons, Columbia University, New York (Fig. 1). His interests were in the neurochemical area (Lorand 2002). After initial studies about lipid composition of the nervous tissue and glutamate metabolism in the brain, he decided to check the hypothesis that permanent binding of neurotransmitters to proteins at the postsynaptic level might be relevant to the metabolism of neurotransmitters themselves, or contribute someway to the physiological effects triggered by neuronal depolarization. The development of radiochemical techniques, in the late 1950s, was crucial for these investigations, as well as for other main biochemical achievements in those years, as the elucidation of the biosynthetic pathways of cholesterol and of the purine nucleotide ring. During his studies, Waelsch discovered, by one side, that enzymes capable of covalent labeling of proteins by amines were present in brain extracts and that their activity was dependent on the addition of calcium ions, but also that their activities were much higher in other tissues, such as liver. These observations were reported by N. K. Sarkar, D. D. Clarke and H. Waelsch in 1957 as a short note in Biochim. Biophys. Acta, under the title "An enzymically catalyzed incorporation of amines into proteins" (Sarkar et al. 1957). This finding, by one side, refuted the original idea, since the phenomenon was not tissue-specific. By the other side, it opened the way to a fruitful research field in which many researchers are still active. Waelsch was immediately fascinated by this process (Clarke et al. 1959) and he studied it in detail, discovering that it was linked to protein crosslinkage as well as to deamidation of glutamine residues in proteins by mechanisms which were reminiscent of those of proteinases (Pincus and Waelsh 1968). Indeed, when insulin was used as a substrate for transglutaminase, it was observed that ammonia was enzymatically released in the absence of amine (Micek et al. 1959). The same behavior was observed by Folk and Cole (1965) using synthetic 


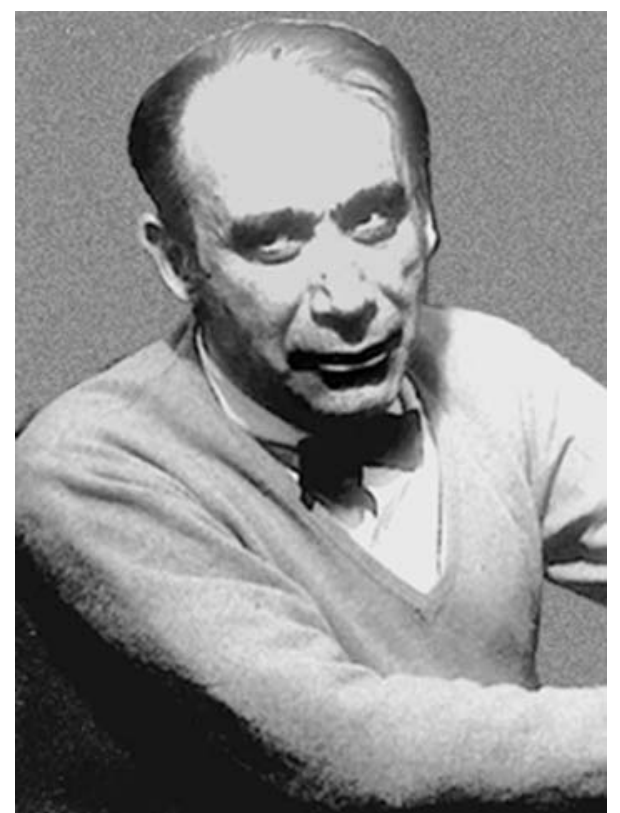

Fig. 1 Heinrich B. Waelsch (1905-1966) MD, ScD, whose group discovered transglutaminase, was chief of Psychiatric Pharmacology Research at the New York State Psychiatric Institute and Director for Neurochemistry at Manhattan State Hospital

blocked glutamine dipeptides and in the case of many proteolytic enzymes that catalyze both hydrolytic and transpeptidation reactions (Mycek and Fruton 1957). These observations raised the question of whether the biological role of transglutaminase is one of hydrolysis or transamidation. If the mechanism of action of transglutaminase is such that the second substrate (water or an amine) reacts directly with the enzyme substrate complex, rather than first binding to the enzyme, then the transamidation reaction would represent a successful competition of an amine over water for the enzyme substrate complex, when an amine is present in the reaction mixture. If this were the case, then the amount of ammonia released would be greater than the amount of amine incorporated, since hydrolysis and transpeptidation could occur simultaneously as seen in the case of papain (Johnston et al. 1950). However, using carbobenzoxy L-glutaminyl glycine and ethanolamine as substrates for transglutaminase, Folk and Cole (1965) showed that all of the ammonia released can be accounted for by transamidation.

Waelsch was outstanding, considering the limited tools available in the field at this early time. At this purpose, we would like to mention Laszlo Lorand (Fig. 2), John E. Folk (Fig. 3) and George E. Rogers, who all joined transglutaminase while investigating other fields, respectively, blood clot formation and stabilization to avoid hemorrhage (Lorand 2005), proteinases which cleave rather than form peptide bonds (Folk and Cole 1965), or stabilization of keratins during skin development (Rothnagel and Rogers

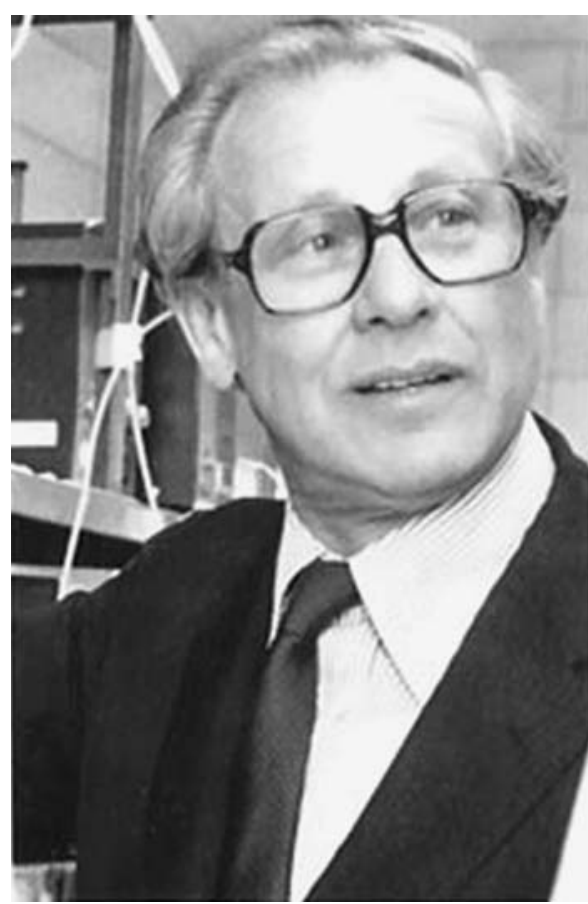

Fig. 2 Laszlo Lorand (NIH MERIT Award, 1989-1998), Research Professor Emeritus at the Cell and Molecular Biology Department and Distinguished Investigator at the Feinberg Cardiovascular Research Institute of the Northwestern University Medical School, Chicago, IL, USA. He was a pioneer scientist in the investigation of the intricate reactions and regulatory processes of blood coagulation. His research is currently carried out on the molecular mechanisms of the protein crosslinking of transglutaminases and their role in aging, cataract formation, neurodegenerative diseases, terminal differentiation, apoptosis and celiac disease

1984). It is still a matter of surprise the ability of these few researchers to get so deep insights into the intimate biology of transglutaminases. They were really wonderful biochemists and excellent scientists. Since most of their original opinions are still valid today, they also speculated clearly about the future of transglutaminase. This is proved for instance by the Waelsch's intuition that transglutaminase is involved in neural pathological processes, as experimental allergic encephalitis, a hypothesis which is still alive nowadays (Wajda et al. 1967; Lorand 2002).

A special care of these pioneers was to develop methods to measure the enzyme activity by means of colorimetric, fluorescent or radiochemical methods, employing suitable peptidyl substrates which had been modified to decrease the number of free lysine amino groups by acetylation, succinylation or dimethylation, to force incorporation of soluble amines into the substrate proteins (insulin and casein were preferred acceptors) (Lorand et al. 1971; Folk and Chung 1985). These technical progresses were instrumental in starting the age of direct protein investigation because it is important "Not to waste clean thoughts on dirty enzymes". This is what Arthur Kornberg used to say 


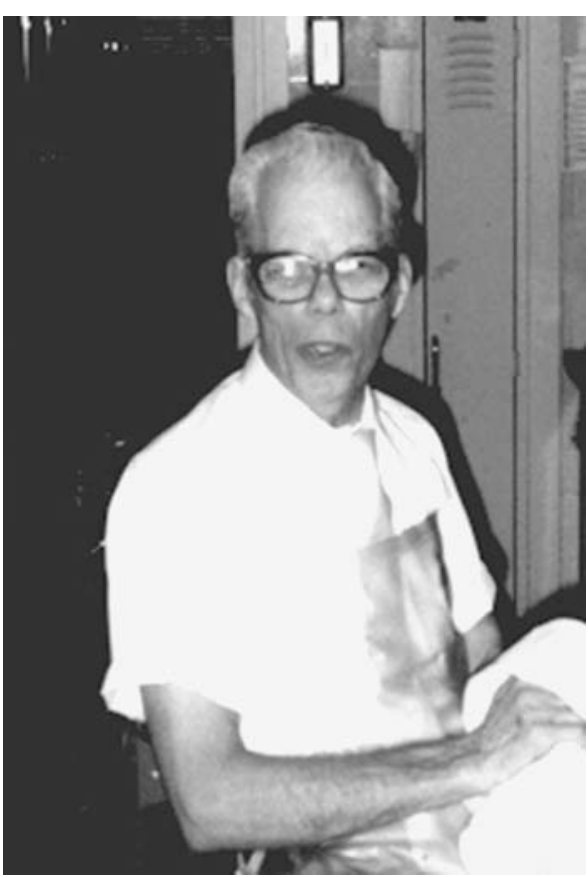

Fig. 3 John E. Folk was chief of the Enzyme Chemistry Section of the National Institute of Dental Research at the National Institutes of Health, Bethesda, MD, USA. After 44 years at NIDR, Folk recently retired as the section's chief, but will continue his affiliation with NIDR as a scientist emeritus. Much of his earliest work was focused on proteolytic enzymology. During the past three decades, he has described the metabolism of transglutaminases and helped to clarify their role. His studies added new information on the function of these enzymes in wound healing and blood clotting, and in hair and skin formation

as it is recalled in an issue of Nature Structure and Molecular Biology, January this year (Rowen 2008; Fuller 2008).

\section{The years of the protein}

The first standardized procedure for successful isolation of transglutaminase from a tissular extract was that developed in the laboratory of John E. Folk, at NIH, which was certainly one of the main laboratories active in transglutaminase research (Folk and Chung 1985). The source of enzyme was guinea pig liver (GPL), since it contains an amount of enzyme which largely exceeds that present in other tissues. With this preparation, a number of properties were checked, including substrate specificity, activation by metals, involvement of thiol groups in the catalytic cycle, catalytic mechanism as a modified ping-pong mechanism, etc. (Folk and Chung 1973). Thus, basically the main properties of GPL transglutaminase were determined and represented a constant term of comparison when taking into account the same enzyme from other districts. The main transglutaminases which were investigated during the 1970s were those from blood plasma (i.e. Factor XIII, which was a main research target in Lorand's and in Folk's labs in Hungary and USA, respectively) (Chung and Folk 1972; Curtis and Lorand 1976), from skin (which appeared to contain at least three forms of enzyme, one soluble, one particulate and one requiring proteolytic digestion to display catalytic activity) (Peterson et al. 1983), and from prostatic secretion, which apparently was independent of calcium for catalytic activity (Esposito et al. 1996). These observations and the occurrence of forms of variable molecular weight were variously interpreted as indicative of either the occurrence of isoenzymes or alternatively of processing during isolation.

In the early and mid- 1980s, definite evidence of the existence of isoenzymes was achieved as it was verified that transglutaminases from tissues (what is now known as type 2 transglutaminase) and from skin had distinct thermal stability at alkaline $\mathrm{pH}$ and responded inversely to transcriptional inducers, notably retinoids (Moore et al. 1984; Lichti et al. 1985). These observations were carried out largely in the labs headed by Peter Davies (type 2 transglutaminase), and by Howard Green and Peter Steinert, who focused on transglutaminase 1 in skin (Fuchs and Green 1981; Yuspa et al. 1982; Davies et al. 1988). The years of the retinoids were crucial in understanding regulation of tissue levels of transglutaminase and their correlations with cell cycling in a physiological perspective, but they were at the same time frustrated by a lack of information on the structural features of the "enzymes". A major information arising in those years was the observation by Charlie Greenberg that the transamidating activity of transglutaminase 2 was inhibited by GTP in an allosteric fashion (Achyuthan and Greenberg 1987; Greenberg et al. 1991). This property, later confirmed in other labs (Bergamini 1988) and considered initially a landmark of transglutaminase 2-while it is known now that it is shared by other enzymes, e.g. types 3 and 5 transglutaminases-represented the basis to understand in the intimate details the regulation of transglutaminase 2 , thanks to the determination of the sequence of several transglutaminases and of the 3D structure of the first transglutaminase to be determined in the crystallin state, Factor XIIIa, whose catalytic subunit had been preparated in the recombinant state at Zymogenetics Inc. in Seattle. This information was instrumental to elucidate the structure of other transglutaminases, looking at the catalytic cycle itself (identifying a proteinase-like catalytic triade and the residues involved in the stabilization of the catalytic intermediate), the roles of natural or induced mutations and finally the relevance of conformational changes in the regulation of the catalytic activity (Griffin et al. 2002). 


\section{The years of the products}

The interest in the identification of products is central in any enzymatic system involved in reactions of protein modification, since it is commonly believed that the physiological effects are triggered by alterations in the properties of the first protein substrate of the involved enzyme. In this respect, investigations have been very hard in the case of transglutaminases, because these enzymes form insoluble protein aggregates (which can include many different proteins) whose resolution into original peptides is very hard to obtain.

Also the rules which govern selection of the aminoacid side chain which must undergo modification are unclear (Esposito and Caputo 2005; Keresztessy et al. 2006). The general feeling is that specificity for Gln residues is rather strict, while it is much less restricted for the amino donor group, so that either Lys side chains or soluble amines (or even water) might act as acyl acceptors. Obviously, both Gln and Lys residues must be exposed on the surface of the target protein, but this condition is not sufficient for selection of single aminoacids as enzyme targets. Also the surrounding sequence has definite effects either increasing or decreasing reactivity, but probably it is the 3D structure which is important, since denatured proteins are usually better substrates than native ones. Another point which must be recalled is that different transglutaminases select distinct Gln residues in the same protein substrate, i.e. these enzymes have differences in substrate recognition, which must depend on different structures at a recognition subdomain at the active center (Fesus et al. 1986). Comparison with recognition by proteinases have been searched to from the very early time, particularly in John E. Folk's lab at NIH, as summarized in 1977 in a well-known review by Folk and Fynlayson in Advances in Protein Chemistry (Folk and Fynlayson 1977; Gorman and Folk 1984), and has been confirmed thereafter by detection of the cysteine proteinase catalytic triad at the active site (Pedersen et al. 1994) and by more recent comparison of properties of sequences targeted by transglutaminase and proteinases.

A special point was represented by the identification of polyamines as amino substrates (Folk et al. 1980) because binding of polyamines (notably spermidine and spermine) is likely to alter consistently the surface properties of the target protein, because it converts an electrically neutral into a positively charged region (Beninati et al. 1988). This change could obviously modify functional properties of modified proteins with either "loss" (the usual response) or alternatively "gain" of function as it happens with HIV-1 aspartyl protease (Beninati and Mukherjee 1992) and phospholipase $\mathrm{A}_{2}$ (Cordella-Miele et al. 1993).

In most instances, researchers focused only on identification of proteins acted upon, disregarding the sequence of the peptides containing reactive Gln and Lys residues, an information which would be worthily for the evaluation of the rules of substrate recognition. Looking back to the nature of the proteins which can be modified-and usually polymerized by transglutaminases, either directly through

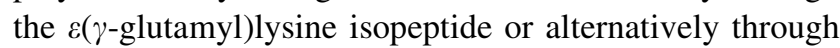
the bis-( $\gamma$-glutamyl)polyamine bridge-it appears they include both intracellular and extracellular proteins (Esposito and Caputo 2005). Among intracellular proteins, investigators have detected enzymes involved in energy metabolism, proteins in signal transduction (e.g. histones and cytokines) but mostly proteins of the contractile and cytoskeletal system. The extracellular proteins are prevalently involved in the organization of the extracellular matrix, as exemplified by studies, among others, of Lorand, Griffin and Belkin (Lorand and Graham 2003; Skill et al. 2004; Verderio et al. 2005; Zemskov et al. 2006).

Our feeling, however, is that identification of protein substrate-product relationships and of their functional significance is still at its dawn, despite the recent application of the most advanced techniques as proteomic analysis, as elegantly carried out by Carla Esposito (Esposito and Caputo 2005).

\section{The years of the gene}

In early 1980s, the attention of researchers focused on the transcriptional regulation of transglutaminase expression, with identification of new ORF sequences coding for unknown isoenzymes (Aeschlimann and Thomazy 2000) and production of $\mathrm{KO}$ animals to study functional features in vivo or in vitro in cultured cells. The original data were obtained thanks to the efforts of Peter Davies, who noted the induction of transglutaminase and the differentiation of monocytes and HL-60 cell line into macrophages during treatment with retinoids (Davies et al. 1985; Nagy et al. 1998). This phenomenon was accompanied by a marked induction of transglutaminase which occurred in vitro as well as in vivo in most cell types. During the years, it became clear that the enzyme overexpression occurred during phases of embryonic cell regression in organogenesis (e.g. in the foot interdigital membranes), that this same process could appear during regression after experimental induction of tissue hypertrophy (as proved by Laszlo Fesus in the liver of animals treated in vivo with lead salts) (Fesus et al. 1987) and that in all these instances the death of the cells took place by apoptosis (Fesus et al. 1991, 1996). This link between transglutaminase 2 and programmed cell death has deeply influenced all successive transglutaminase research, including manipulation of transglutaminase expression for therapeutic goals, as occurred in the treatment of certain forms of leukemia (typically the 
promyelocytic leukemia, in which two cycles of treatment are effective in healing definitively over $85 \%$ of the patients) (Benedetti et al. 1996; Ozpolat et al. 2001; Asou 2007). A very large interest is spreading now in the involvement of transglutaminases in inflammatory (Sohn et al. 2003), neoplastic (Lentini et al. 2004; Mangala and Mehta 2005), and epidermal (Eckert et al. 2005) diseases.

Researchers took also advantage of the proved sensitivity of the transglutaminase promoter to retinoids to study the structure of the gene and its organization into introns and exons and to identify additional putative ORF sequences, thus obtaining evidence of additional possible genes. In this way, additional putative forms of transglutaminase have been identified (notable transglutaminase 7) but most of them still await a full characterization. As a corollary to these studies, G. Melino in Italy and R. Graham in Australia planned and succeeded to develop KO animals deleted for the gene coding for transglutaminase 2 $\left(T g 2^{-/-}\right.$) (De Laurenzi and Melino 2001; Nanda et al. 2001). Surprisingly, these animals had normal breeding, survival and phenotype, and this was interpreted as a sign of compensation by other forms of transglutaminase whose expression is left unaltered in $\mathrm{KO}$ animals, although it is now known that these animals have defects in insulin secretion and phagocytosis. Interest in transglutaminase transgenic animals is still increasing: additional mutants devoid of factor XIII are available (Koseki-Kuno et al. 2003) and animals ablated of transglutaminase 3 activity have been reported at the Marrakesh meeting (Thiebach et al. 2007).

\section{The years of disease}

$\mathrm{KO}$ animals represent clearly a valuable tool to test the involvement of transglutaminases in the pathogenesis of diseases, e.g. transglutaminase 2 in vascular remodeling in hypertension (Pistea et al. 2008) and Factor XIIIa in ventricular remodeling and survival after AMI (Vanhoutte and Heymans 2008). In these instances, the aim was to prove a beneficial role of the enzyme, so that animals with loss of function developed an anomalous condition. In other instances, however, the role of transglutaminases in disease is emerging as a situation of disrupted excessive expression or activity. This has appeared to be the case in neurodegenerative diseases (Bailey et al. 2005) in which excessive or abnormal aggregated proteins are accumulated inside the neurons and are paralleled by an increased enzyme activity, resulting from either overexpression, or expression of constitutively active forms (not requiring calcium activation or alternatively insensitive to inhibition by GTP) or finally accumulation of substrate proteins. However, it has been shown that the pathogenetic role of transglutaminase
2 in neurodegenerative diseases is very complex and is not related to the assembly of these protein inclusion bodies (Mastroberardino et al. 2002). These lesions take place in several chronic neurodegenerative diseases, including Huntington, Parkinson and Alzheimer disease, as well as multiple sclerosis (Muma 2007; Wilhelmus et al. 2008). In these instances, the therapeutic goal must be that to reduce the activity in vivo by means of specific inhibitors of transcription or of activity (we come back by years!).

The major interest between transglutaminases and disease, however, is linked to targeting the protein by antibodies in autoimmune diseases. All this started in the late 1990s, when Schuppan et al. demonstrated that serum from patients affected by celiac disease (CD) interacts with a protein present in tissue homogenates (Schuppan et al. 1998). This protein was sequenced and proved identical with human transglutaminase 2 (Dieterich et al. 1997). The relevance of these findings was immediately apparent when it was proved that the titer of the anti-transglutaminase antibodies correlated with the clinical staging (regression or relapse), and that it was reliable to monitor the patient's compliance to the dietetic therapy. However, the real pathogenetic link between the immune response and the pathogenesis of CD is still foggy, despite the hundreds of reports (now repetitive) describing the reliability of the determination of transglutaminase autoimmunity in diagnosis of CD. In addition, it is emerging that antitransglutaminase antibodies are also raised in a few other autoimmune conditions, including heart failure, thyroid and articular diseases (Ch'ng et al. 2005; Sane 2008).

\section{Personal recollections}

Ourselves, we have been interested in transglutaminases for nearly 30 years. So we were not in the front at the time, but we were close to it. Each of us had a personal way of entry, his satisfactions and his delusions. For Carlo Bergamini, the way in was mediated by Prof. Mario Rippa, a nice protein chemist, who knew personally John E. Folk and was attracted by these enzymes, "which looks to make so many things (indeed many roles of transglutaminases in the early 1980s were far from imaging), and is similar to proteases, but we know so little about.... Carlo, have a look at it! It should be fine...". And actually it was, as it is always to look in the back corners (even without light) as in the attic of my country house. Within time, Carlo got contact with so many friends, never working directly under the guide of a pioneer, although getting familial with Laszlo Lorand, who obtained the HC graduation in Medicine at the University of Ferrara for his studies on Factor XIII. 
The contact with transglutaminase was tastier for Simone Beninati and Mauro Piacentini. Simone in early 1980, in collaboration with Mauro, under the supervision of the lab chief Prof. Francesco Autuori, was preparing a manuscript dealing with the identification of polyamines covalently linked to proteins in rat liver (Beninati et al. 1985). The manuscript was submitted to the journal "Biochimica et Biophysica Acta" but, according to the observations of the referees, it was not suitable for publication. One referee requested some new experiments for collection of supplementary evidences. Simone and Mauro were working at the Institute of Histology and Embriology of the University of Rome La Sapienza and unfortunately at that time the laboratory was not suitable for the suggested experiments. These difficulties were communicated to the referee. He replied inviting them in his laboratory at the National Institute of Health, Bethesda, MD, USA, where they went for the first time in the summer of 1984. Surprisingly, they discovered that the referee was John E. Folk, one of the fathers of transglutaminase. Simone decided to come back in John's lab where he spent 6 years of the most exciting part of his scientific life. Soon after his arrival, he joined the NIH team in an investigation which was the beginning of his work on transglutaminase and polyamines. At NIH, during the years spent in Folk's lab, he came to appreciate the important role played by transglutaminase 2 in cell differentiation and neoplastic growth (Beninati et al. 1993; Lentini et al. 2000, 2004). Simone returned to the University of Rome "Tor Vergata" campus in 1992.

Mauro's interest in transglutaminase field started when he met Simone at the University of Rome "La Sapienza" and decided to join him in 1974 for studying the role of polyamines in cancer. During that time, he started to be interested in the possible role of transglutaminases as mediators of their incorporation into proteins. As mentioned by Simone, we did not have the possibility in the lab at that time to detect the $\gamma$-glutamyl-polyamine derivatives, so we moved in John E. Folk's lab. During his second stage in Folk's lab, in 1986, Mauro had the chance to become acquainted with Laszlo Fesus who was also spending a period of time there, having the opportunity to discuss the biological role of transglutaminase in mammalian cells and to start a very profitable collaboration (Fesus and Piacentini 2002). At that time, Mauro was investigating the role of transglutaminase 2 in terminal differentiation of keratinocytes (Piacentini et al. 1988) a highly specialized form of cell death. That experience has created the basis for the following exciting 20 years, during which Mauro's major interest has been to dissect out the role of transglutaminase 2 in the various forms of cell death under normal and pathological settings (Mastroberardino et al. 2002).

\section{Conclusions}

We would like to conclude this short and not comprehensive editorial with a few personal considerations about our field. Unfortunately, not too many scientists have been attracted by this enzyme family in the last 30 years and this is quite strange, considering its involvement in the most important cellular functions and human pathology, as well as its important biotechnological applications. This is still a small field which we hope will grow soon, in this respect we believe that the recent announcement of the first Gordon Research Conference on "Transglutaminases in Human Disease Processes", that will be held in the summer of 2010 in USA, will represent an important step forward.

We believe that the story of the transglutaminase research field is not a special one and very likely similar to that of many other scientific fields of investigation, however, we would like to finish saying that "it is a pleasure to have been, and to continue to be, a participant in this experience".

\section{References}

Achyuthan KE, Greenberg CS (1987) Identification of a guanosine triphosphate-binding site on guinea pig liver transglutaminase. Role of GTP and calcium ions in modulating activity. J Biol Chem 262:1901-1906

Aeschlimann D, Thomazy V (2000) Protein crosslinking in assembly and remodelling of extracellular matrices: the role of transglutaminases. Connect Tissue Res 41:1-27

Asou N (2007) All-trans retinoic acid in the treatment of acute promyielocytic leukemia. Intern Med 46(2):91-93

Bailey CD, Tucholski J, Johnson GV (2005) Transglutaminases in neurodegenerative disorders. Prog Exp Tumor Res 38:139-157

Benedetti L, Grignani F, Scicchitano BM, Jetten AM, Diverio D, Lo Coco F, Avvisati G, Gambacorti-Passerini C, Adamo S, Levin AA, Pelicci PG, Nervi C (1996) Retinoid-induced differentiation of acute promyelocytic leukemia involves PML-RARalphamediated increase of type II transglutaminase. Blood 87:1939-1950

Beninati S, Abbruzzese A, Cardinali M (1993) Differences in the posttranslational modification of proteins by polyamines between weakly and highly metastatic B16 melanoma cells. Int J Cancer 53:792-797

Beninati S, Mukherjee AB (1992) A novel transglutaminase-catalyzed posttranslational modification of HIV-1 aspartyl protease. Biochem Biophys Res Commun 187(3):1211-1218

Beninati S, Piacentini M, Argento-Cerù MP, Russo-Caia S, Autuori F (1985) Presence of di- and polyamines covalently bound to protein in rat liver. Biochim Biophys Acta 841(1):120-126

Beninati S, Piacentini M, Cocuzzi ET, Autuori F, Folk JE (1988) Covalent incorporation of polyamines as gamma-glutamyl derivatives into $\mathrm{CHO}$ cell protein. Biochim Biophys Acta 952(3):325-333

Bergamini CM (1988) GTP modulates calcium binding and cationinduced conformational changes in erythrocyte transglutaminase. FEBS Lett 239:255-258 
Ch'ng CL, Biswas M, Benton A, Jones MK, Kingham JG (2005) Prospective screening for coeliac disease in patients with Graves' hyperthyroidism using anti-gliadin and tissue transglutaminase antibodies. Clin Endocrinol 62(3):303-306

Chung SI, Folk JE (1972) Kinetic studies with transglutaminases. The human blood enzymes (activated coagulation factor 13 and the guinea pig hair follicle enzyme. J Biol Chem 247(9):2798-2807

Clarke DD, Neidle A, Sarkaar NK, Waelsch H (1959) Metabolic activity of protein amide groups. Arch Biochem Biophys 79:277-279

Cordella-miele E, Miele L, Beninati S, Mukherjee AB (1993) Transglutaminase-catalyzed incorporation of polyamines into phospholipase $A_{2}$. J Biochem 113:164-173

Curtis CG, Lorand L (1976) Fibrin-stabilizing factor (factor XIII). Methods Enzymol 45:177-191

Davies PJ, Chiocca EA, Stein JP (1988) Retinoid-regulated expression of tissue transglutaminase in normal and leukemic myeloid cells. Adv Exp Med Biol 231:63-71

Davies PJ, Murtaugh MP, Moore WT Jr, Johnson GS, Lucas D (1985) Retinoic acid-induced expression of tissue transglutaminase in human promyelocytic leukemia (HL-60) cells. J Biol Chem 260:5166-5174

De Laurenzi V, Melino G (2001) Gene disruption of tissue transglutaminase. Mol Cell Biol 21(1):148-155

Dieterich W, Ehnis T, Bauer M, Donner P, Volta U, Riecken EO, Schuppan D (1997) Identification of tissue transglutaminase as the autoantigen of celiac disease. Nat Med 3:797-801

Eckert RL, Sturniolo MT, Broome AM, Ruse M, Rorke EA (2005) Transglutaminase function in epidermis. J Invest Dermatol 124:481-492

Esposito C, Caputo I (2005) Mammalian transglutaminases. Identification of substrates as a key to physiological function and physiopathological relevance. FEBS J 272(3):615-631

Esposito C, Pucci P, Amoresano A, Marino G, Cozzolino A, Porta R (1996) Transglutaminase from rat coagulating gland secretion. Post-translational modifications and activation by phosphatidic acid. J Biol Chem 271(44):27416-27423

Fesus L, Davies PJ, Piacentini M (1991) Apoptosis: molecular mechanisms in programmed cell death. Eur $\mathrm{J}$ Cell Biol 56(2):170-177

Fesus L, Madi A, Balajthy Z, Nemes Z, Szondy Z (1996) Transglutaminase induction by various cell death and apoptosis pathways. Experientia 52:942-949

Fesus L, Metsis ML, Muszbek L, Koteliansky VE (1986) Transglutaminase-sensitive glutamine residues of human plasma fibronectin revealed by studying its proteolytic fragments. Eur J Biochem 154:371-374

Fesus L, Piacentini M (2002) Transglutaminase 2: an enigmatic enzyme with diverse functions. Trends Biochem Sci 27(10):534-539

Fesus L, Thomazy V, Falus A (1987) Induction and activation of tissue transglutaminase during programmed cell death. FEBS Lett 224:104-108

Folk JE, Chung SI (1973) Molecular and catalytic properties of transglutaminases. Adv Enzymol Relat Areas Mol Biol 38:109_ 191

Folk JE, Chung SI (1985) Transglutaminases. Methods Enzymol 113:358-375

Folk JE, Cole PW (1965) Structural requirements of specific substrates for guinea pig liver transglutaminase. J Biol Chem 240:2951-2960

Folk JE, Fynlayson JS (1977) The epsilon-(gamma-glutamyl)lysine crosslink and the catalytic role of transglutaminases. Adv Protein Chem 31:1-133

Folk JE, Park MH, Chung SI, Schrode J, Lester EP, Cooper HL (1980) Polyamines as physiological substrates for transglutaminases. J Biol Chem 255:3695-3700
Fuchs E, Green H (1981) Regulation of terminal differentiation of cultured human keratinocytes by vitamin A. Cell 25(3):617-625

Fuller RS (2008) A tribute to Arthur Kornberg 1918-2007. Nat Struct Mol Biol 15(1):2-17

Gorman JJ, Folk JE (1984) Structural features of glutamine substrates for transglutaminase. J Biol Chem 259(14):9007-9010

Greenberg CS, Birckbickler PJ, Rice RH (1991) Transglutaminases: multifunctional cross-linking enzymes that stabilize tissues. FASEB J 5(15):3071-3077

Griffin M, Casadio R, Bergamini CM (2002) Transglutaminases: nature's biological glues. Biochem J 368:377-396

Johnston RJ, Micek MJ, Fruton JS (1950) Catalysis of transamidation reactions by proteolytic enzymes. J Biol Chem 185:629-641

Keresztessy Z, Csosz E, Hársfalvi J, Csomós K, Gray J, Lightowlers RN, Lakey JH, Balajthy Z, Fesus L (2006) Phage display selection of efficient glutamine-donor substrate peptides for transglutaminase 2. Protein Sci 15:2466-2480

Koseki-Kuno S, Yamakawa M, Dickneite G, Ichinose A (2003) Factor XIII A subunit-deficient mice developed severe uterine bleeding events and subsequent spontaneous miscarriages. Blood 102:4410-4412

Lentini A, Abbruzzese A, Caraglia M, Marra M, Beninati S (2004) Protein-polyamine conjugation by transglutaminase in cancer cell differentiation. Amino Acids 26(4):331-337

Lentini A, Autuori F, Mattioli P, Caraglia M, Abbruzzese A, Beninati S (2000) Evaluation of the efficacy of potential antineoplastic drugs on tumour metastasis by a computer-assisted image analysis. Eur J Cancer 36(12):1572-1577

Lichti U, Ben T, Yuspa SH (1985) Retinoic acid-induced transglutaminase in mouse epidermal cells is distinct from epidermal transglutaminase. J Biol Chem 260:1422-1426

Lorand L (2002) Transglutaminase: remembering Heinrich Waelsch. Neurochem Int 40:7-12

Lorand L (2005) Factor XIII and the clotting of fibrinogen: from basic research to medicine. J Thrombosis Hemostasis 3:1337-1348

Lorand L, Graham RM (2003) Transglutaminases: crosslinking enzymes with pleiotropic functions. Nat Rev Mol Cell Biol 4(2):140-156

Lorand L, Lockridge OM, Campbell LK, Myhrman R, Bruner-Lorand J (1971) Transamidating enzymes II A continuous fluorescent method suited for automating measurements of Factor XIII in plasma. Anal Biochem 44:221-231

Mangala LS, Mehta K (2005) Tissue transglutaminase (TG2) in cancer biology. Prog Exp Tumor Res 38:125-138

Mastroberardino PG, Iannicola C, Nardacci R, Bernassola F, De Laurenzi V, Melino G, Moreno S, Pavone F, Oliverio S, Fesus L, Piacentini M (2002) 'Tissue' transglutaminase ablation reduces neuronal death and prolongs survival in a mouse model of Huntington's disease. Cell Death Differ 9(9):873-880

Micek MJ, Clarke DD, Neidle A, Waelsch H (1959) Amine incorporation into insulin as catalyzed by transglutaminase. Arch Biochem Biophys 84:528-540

Mycek MJ, Fruton JS (1957) Specificity of papain-catalyzed transamidation reactions. J Biol Chem 226(1):165-171

Moore WT, Murtaugh MP, Davies PJ (1984) Retinoic acid-induced expression of tissue transglutaminase in mouse peritoneal macrophages. J Biol Chem 259(20):12794-12802

Muma NA (2007) Transglutaminase is linked to neurodegenerative diseases. J Neuropathol Exp Neurol 66(4):258-263

Nagy L, Thomazy VA, Heyman RA, Davies PJ (1998) Retinoidinduced apoptosis in normal and neoplastic tissues. Cell Death Differ 5(1):11-19

Nanda N, Iismaa SE, Owens WA, Husain A, Mackay F, Graham RM (2001) Targeted inactivation of $\mathrm{Gh} /$ tissue transglutaminase II. J Biol Chem 276(23):20673-20678 
Ozpolat B, Lopez-Berestein G, Mehta K (2001) ATRA(ouble) in the treatment of acute promyelocytic leukemia. J Biol Regul Homeost Agents 15(2):107-122

Pedersen LC, Yee VC, Bishop PD, Le Trong I, Teller DC, Stenkamp RE (1994) Transglutaminase factor XIII uses proteinase-like catalytic triad to crosslink macromolecules. Protein Sci 3(7):1131-1135

Peterson LL, Zettergren JG, Wuepper KD (1983) Biochemistry of transglutaminases and cross-linking in the skin. J Invest Dermatol 81(1 Suppl):95S-100S

Piacentini M, Martinet N, Beninati S, Folk JE (1988) Free and proteinconjugated polyamines in mouse epidermal cells. Effect of high calcium and retinoic acid. J Biol Chem 263(8):3790-3794

Pincus JH, Waelsh H (1968) The specificity of transglutaminase II. Structural requirements of the amine substrate. Arch Biochem Biophys 126(1):44-52

Pistea A, Bakker EN, Spaan JA, Hardeman MR, van Rooijen N, VanBavel E (2008) Small artery remodeling and erythrocyte deformability in L-NAME-induced hypertension: role of transglutaminases. J Vasc Res 45:10-18

Rothnagel JA, Rogers GE (1984) Transglutaminase-mediated crosslinking in mammalian epidermis. Mol Cell Biochem 58(12):113-119

Rowen L (2008) A tribute to Arthur Kornberg. Nature Struct Mol Biol 15:10

Sane DC (2008) Antibodies to tissue transglutaminase: an immune link between the gut, the coronaries and the myocardium? J Intern Med 263(1):1-3

Sarkar NK, Clarke DD, Waelsh H (1957) An enzymically catalyzed incorporation of amines into proteins. Biochim Biophys Acta 25:451-452

Schuppan D, Dieterich W, Ehnis T, Bauer M, Donner P, Volta U, Riecken EO (1998) Identification of the autoantigen of celiac disease. Ann N Y Acad Sci 859:121-126
Skill NJ, Johnson TS, Coutts IG, Saint RE, Fisher M, Huang L, El Nahas AM, Collighan RJ, Griffin M (2004) Inhibition of transglutaminase activity reduces extracellular matrix accumulation induced by high glucose levels in proximal tubular epithelial cells. J Biol Chem 279:47754-47762

Sohn J, Kim TI, Yoon YH, Kim JY, Kim SY (2003) Novel transglutaminase inhibitors reverse the inflammation of allergic conjunctivitis. J Clin Invest 111:121-128

Thiebach L, John S, Paulsson M, Smyth N (2007) The role of Tg3 and Tg6 in hair morphogenesis and in the establishment of the skin barrier function. Communication at the IX Conference on Transglutaminases and Protein Crosslinking, Marrakech, September 2007

Vanhoutte D, Heymans S (2008) Factor XIII: the cement of the heart after myocardial infarction? Eur Heart J 29:427-428

Verderio EA, Johnson TS, Griffin M (2005) Transglutaminases in wound healing and inflammation. Prog Exp Tumor Res 38:89114

Wajda IJ, Lee JM, Waelsch H (1967) Transglutaminase and experimental allergic encephalomyelitis. The effects of encephalitogenic components in mice and guinea pigs. $\mathrm{J}$ Neurochem 14:389-399

Wilhelmus MM, van Dam AM, Drukarch B (2008) Tissue transglutaminase: a novel pharmacological target in preventing toxic protein aggregation in neurodegenerative diseases. Eur $\mathbf{J}$ Pharmacol 585(2-3):464-472

Yuspa SH, Ben T, Steinert P (1982) Retinoic acid induces tranglutaminase activity but inhibits cornification of cultured epidermal cells. J Biol Chem 257(17):9906-9908

Zemskov EA, Janiak A, Hang J, Waghray A, Belkin AM (2006) The role of tissue tranglutaminase in cell-matrix interactions. Front Biosci 11:1057-1076 